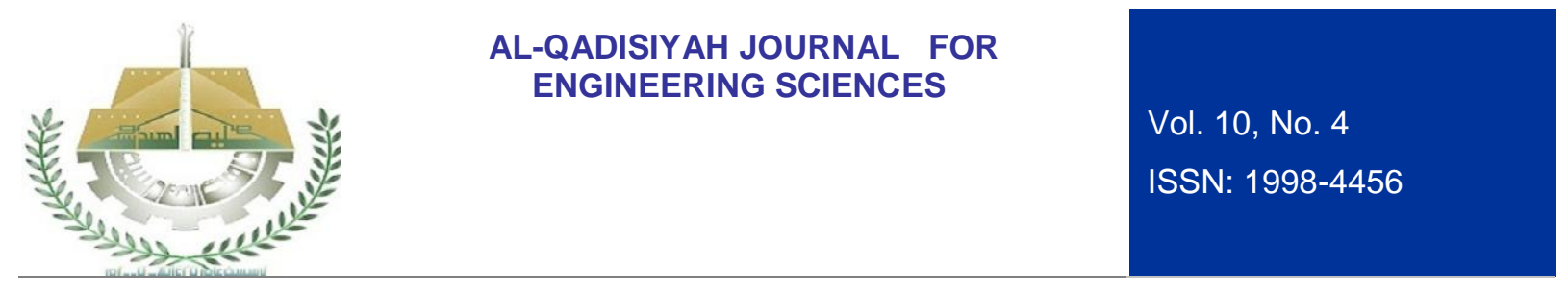

\title{
MEASUREMENT OF LIQUID LEVEL IN PARTIALLY-FILLED PIPES USING A NOISE OF ELECTROMAGNETIC FLOWMETER
}

\author{
Muneer A. Ismael, \\ Department of Mechanical Engineering, Engineering College, University of Basrah, Basrah, IRAQ. \\ E-mail: muneerismael@yahoo.com,muneer.ismael@uobasrah.edu.iq \\ Rafil M. Laftah, \\ Department of Mechanical Engineering, Engineering College, University of Basrah, Basrah, IRAQ. \\ E-mail: drrafil74@gmail.com \\ Mustafa N. Falih, \\ Department of Mechanical Engineering, Engineering College, University of Basrah, Basrah, IRAQ.
} E-mail: mustafa1986@gmail.com

Received on 10 Octobor 2017 Accepted on 13 December 2017 Published on 20 February 2018 DOI: $10.30772 / q j e s . v 10 i 4.504$

\begin{abstract}
This paper investigates the measurement of liquid level in partially filled pipes utilizing an electrical noise signal (transformer signal) generated in electromagnetic flowmeter namely, transformer signal. The study was conducted by experiments and the collected data were analyzed statistically using Artificial Neural Network (ANN). The experimental study was achieved by building a laboratory rig containing the main parts of electromagnetic flowmeter. The main parameters which have been studied were the liquid level, magnetic field strength $(B=0.00809 T, 0.03308 T, 0.05301 T)$, liquid temperature $(T=$ $11^{\circ} \mathrm{C}$ to $\left.21.5^{\circ} \mathrm{C}\right)$ and liquid electrical conductivity $(\sigma=0.11225,3.08,210, \mathrm{mS} / \mathrm{cm})$. The collected data were analyzed using the back propagation neural network technique included in Matlab software 2009. The results show that the transformer signal is greatly influenced by variations of the liquid level inside partially filled electromagnetic flowmeter. The electrode position of $\left(\theta=160^{\circ}\right)$ has had the strongest response to liquid level. The electrode position effect on the transformer signal is the greatest compared with that of the liquid temperature and the strength of the magnetic field. Generally, the transformer signal was found to be an increasing function with decreasing of liquid level.
\end{abstract}

Keywords: electromagnetic flowmeter, Liquid level, partially-filled pipes, noise signal.

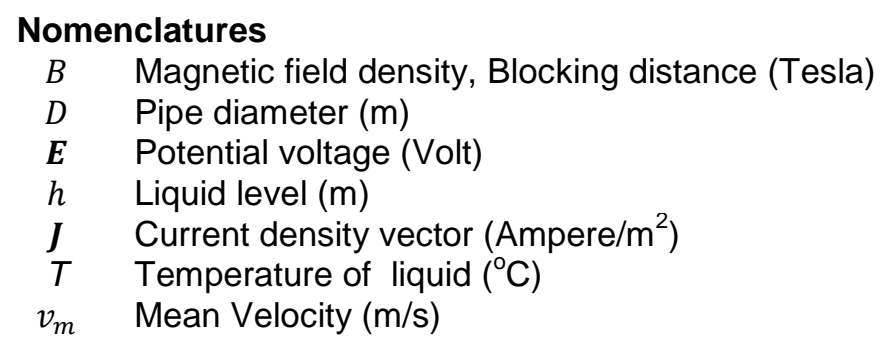




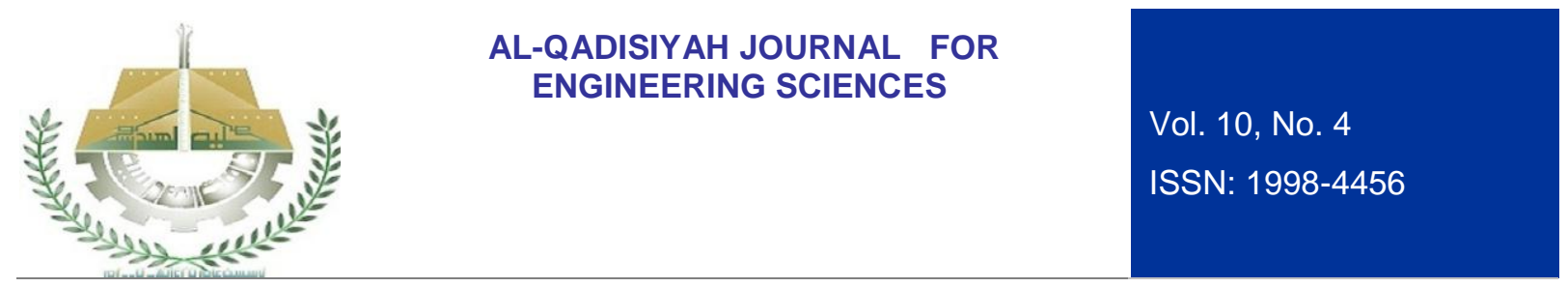

\section{Greek Symbols}

$\sigma \quad$ Electrical conductivity $(\mathrm{mS} / \mathrm{cm})$

$\theta \quad$ Angle of electrode position (degree)

$\mu_{o} \quad$ Magnetic permeability of free space $\left(\mathrm{H} . \mathrm{m}^{-1}\right)$

$\Delta U \quad$ Change of induced signal ( $\mathrm{V}$ )

$\Delta z \quad$ Distance between vertical axis and the twisted wires $(\mathrm{m})$

\section{Abbreviations}

ANNs Artificial Neural Networks

EMF Electro Magnetic Flowmeter

MSE Mean Squared Error

PSD Phase-Sensitive Detector

\section{INTRODUCTION}

Electromagnetic flowmeter (EMF) is a non-invasive device that measures the average velocity and consequently the flow of electrically conductive fluids like water, slurry, conducting chemicals, sewage, liquid metals and liquid foods through a pipe and even in open channels. Its principle of operation is relied on Faraday's law of induction, whereby an electrical field is induced in a moving liquid in the presence of a magnetic field if both the moving liquid and the magnetic field are perpendicular. The EMFs are developed to stand in the measurement of flow through open channel and free surface flows as in partially filled circular pipes. Partially filled pipes are encountered in industry, and especially in drainage and waste pipes carrying radiative and chemical liquids. The electromagnetic flowmeters measure the fluid velocity hence, the flowing area is the determinism to compute the flow rate. Therefore, when the fluid does not completely fill the pipe, additional attention will be needed to the EMF. In 1930, William [1] prepared the first electromagnetic flowmeter-like device when he used the electromagnetic induction to measure the flow of conductive solutions and mercury in closed pipes. In the same year, Kolin [1] suggested the use of electromagnetic induction flowmeter to measure the flow of blood in blood vessels. Hemp [2] introduced a promising study regarding the theory of eddy currents in the electromagnetic flowmeter. He considered the problem of eddy currents and transformer (noise) signals in electromagnetic flowmeter. He gave a procedure for solving this problem. Al-Rabeh [3] and Hemp [4] discussed the ability of dry calibration of the EMF to reduce the expensive real calibration. Bates [5] introduced a novel design of multi-electrode electromagnetic flowmeter. His design provided nine conventional electromagnetic flowmeters housed in a single body to adverse the flow conditions immediately downstream from a header tank.

Rosales and Sanderson [6] provided a model of streaming current noise generated by the interaction of turbulence with charge distribution, which occurs in the liquid, close to the surface of the insulating liner of an electromagnetic flowmeter, because of charge species being absorbed by the lining material itself. Such noise exists whether the electromagnetic field of the flowmeter is exited or not.

Early innovation published works regarding the EMF when the flowing liquid does not completely fill the pipe (partially filled) can be found in [7, 8, and 9]. Bonfig [10] wrote an article prescribing a new development in magnetic flow measurement in partially filled open channels. He suggested that the flow rate is obtained by multiplying an electrical signal proportional to the mean velocity of the liquid and with an electrical signal proportional to the filled cross-section. Barker [11] invented a method for measuring total liquid volume flow in partially full cylindrical pipes, and apparatus for practicing the method. He explained that the total measurement of both flow velocity and liquid level must be made to calculate total volume flow for this condition. Doney [12] constructed an electromagnetic flowmeter worked in partially filled pipes having high accuracy, the ability to handle fluid with high solids content and low maintenance design. Godley [13] reported a document covering the operational information about the flow measurement of water industry in partially filled conduits. He mentioned the most important conditions that constraint the general flow measurement method in such situation. These conditions are due to the hydraulic, impurities in the fluid, physical and environmental. Ismael [14] performed a theoretical analysis and extensive experimental study on partially filled electromagnetic flowmeter. Theoretically, the two main parts of the electromagnetic 


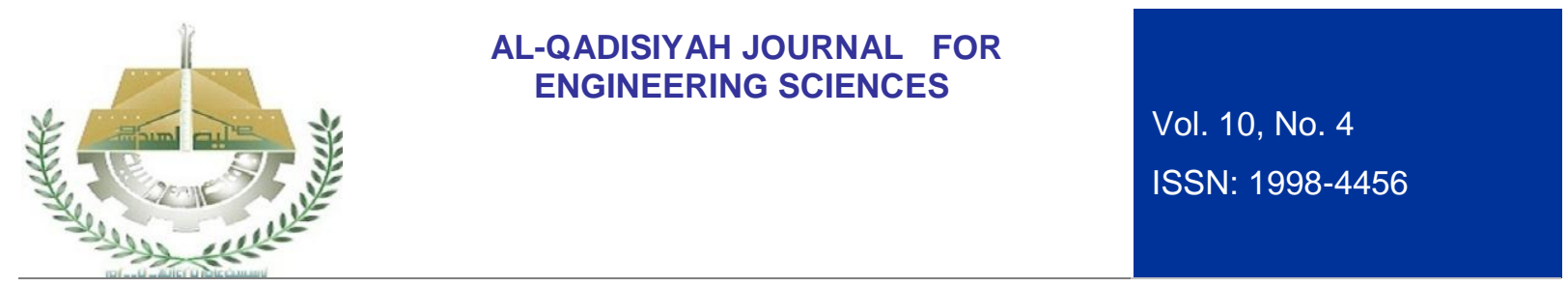

flowmeter were optimized to give a predictable flow signal sensitive to neither changes in the liquid level nor changes in the velocity distribution of the metered liquid for the same flow rate.

Lucas and Leeungculsatien 2010 [15] have used the COMSOL Multiphysics to design the EMF for measuring the velocity profile of single and multiphase flow. They assumed an array of point electrodes, by which the matrix inversion method is utilized to reconstruct the velocity profiles from the output of these electrodes. Ji et al. 2013 [16] have proved by theoretical analysis and experiments the feasibility of the EMF in partially filled pipes. They used arc-shaped electrodes for flow signal and a pair of injection electrodes for detecting the liquid level. Watral et al. 2015 [17] presented and described in detail the EMFs used for open channels and their methods of signal processing. They also discussed the concept of low-energy electromagnetic flowmeter. Justensen 2016 [18] studied the performance of EMF when they installed in different orientations. They found significant shift in the accuracy with different orientation when respect to upstream elbow.

The idea of the present work is to make the EMF measure the liquid level in partially filled circular pipes without any auxiliary sensor. This can be achieved by utilizing some noise signal inherent in the electromagnetic flowmeters namely, transformer noise signal. It is believed that this new technique is better and cheaper than the other techniques provided with EMF, such as ultrasonic level sensor, resistance sensor, and capacitor sensor. Due to our best knowledge, this technique, which may violently reduce the cost of EMF handled in partially filled pipes, has not been discussed in the literature.

\section{BASIC THEORY AND PROBLEM DEFINITION}

The classical theory and principle of the electromagnetic flowmeters is well established and can be found in many references on the subject. The most important of which is an early book by Shercliff in 1962 [19]. The conventional instrument uses a uniform magnetic field and small "point" metal electrodes in an insulating pipe of circular cross-section. This configuration has the advantage that the signal is proportional to the flow rate when the velocity distribution in the liquid inside the flowmeter volume is rectilinear and axisymmetric. In electromagnetic flow-measurement the fluid is assumed to be non-magnetic (has a permeability of free space $\mu_{o}$ ). The fluid is furthermore assumed to obey Ohm's law, so that current flow is proportional and parallel to the electric field referred to axes moving with the fluid, the electrical conductivity $\sigma$ is assumed isotropic and unaffected by the magnetic field or the fluid motion. Currents due to convection of charge by the fluid motion are neglected because such charge (necessary to account for any divergence of the electric displacement in the fluid) has been always very small. Thus, the current flow in the fluid is taken to be governed by Ohm's law in the form [14]:

$$
\boldsymbol{J}=\sigma \cdot(\boldsymbol{E}+\boldsymbol{v} \times \boldsymbol{B})
$$

Where $\boldsymbol{J}$ is the current density vector, $\sigma$ is the conductivity, $\boldsymbol{E}$ is the potential voltage and $\boldsymbol{v}$ is the velocity of liquid. Under specified circumstances, the final form of the equation that prescribes the induced flow signal $(\Delta U)$ in electromagnetic flowmeter can be written in the following form [19]:

$$
\Delta U=B D v_{m} \ldots \ldots \ldots \ldots \ldots
$$

Where $B$ is the applied magnetic field, $D$ is the flowmeter diameter and $v_{m}$ is the fluid mean velocity.

In a partially filled pipes, the domain of eq'n (2) is that the filled portion of the flowmeter volume. Thus, the flow signal induced in the electrodes is the resultant of an infinite number of generators dispersed into the fluid. The output of each generator (Figure 1) is proportional to the local flux density and the local fluid velocity. This output voltage is shunted by the fluid surrounding the generator, as a consequence of which 


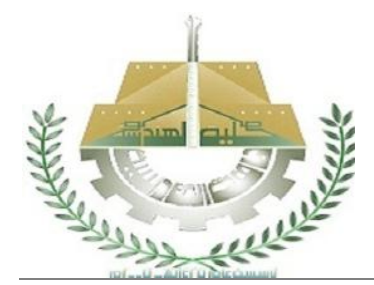

\section{AL-QADISIYAH JOURNAL FOR ENGINEERING SCIENCES}

\section{Vol. 10 , No. 4}

ISSN: $1998-4456$

only a portion of signal is seen at the electrodes. The circuit surrounding the single generator from the top to the bottom of the flow tube may therefore be represented by a network of fluid-equivalent resistors $R$ 's [20].

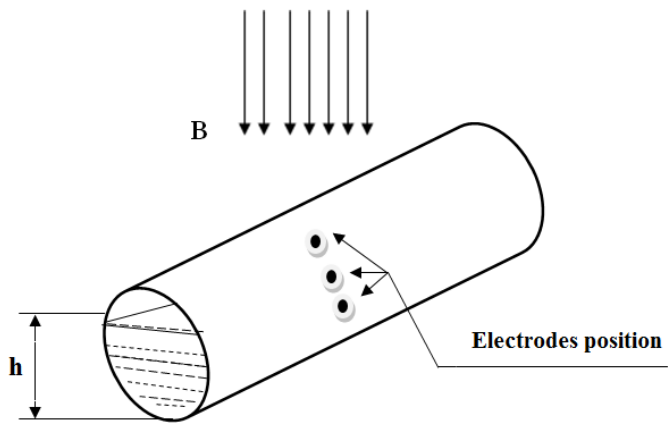

(a)

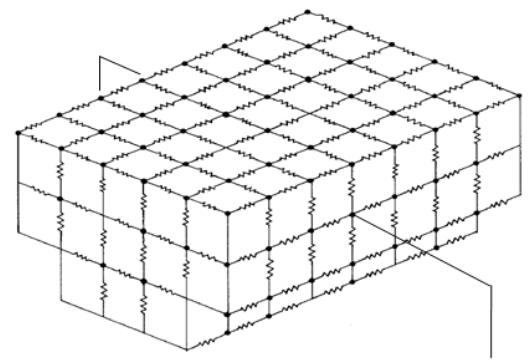

(b)

Figure 1: (a) Uniform magnetic field, (b) Liquid equivalent resistance.

\subsection{NOISE SIGNALS IN ELECTROMAGNETIC FLOWMETER}

Since the present paper concerns with the liquid level measurement, we will make more attention to utilize other influence of variation, the liquid level. It is well known that any electromagnetic flowmeter uses AC magnetic field is incorporated with a noise signal known as "transformer signal". The liquid inside the flowmeter is a major part of the circuit generating the transformer signal, hence, it is expected that the liquid level directly affects this noise signal. The present idea is to utilize the transformer noise as a measure of the liquid level inside the electromagnetic flowmeter pipe. However, there are other noise signals but their order of magnitude is much less than the transformer noise. The conventional electromagnetic flowmeter is carefully designed to avoid most of these noises.

\subsection{TRANSFORMER NOISE}

In order to measure the flow signal, it is necessary to connect wires to the electrodes and lead them out of the flowmeter tube to the detection circuit. This loop leads to the danger of pick-up from external fields and from the electromagnet itself. This noise signal sometimes referred as quadrature voltage because it assumed to be $90^{\circ}$ out of phase with $A C$ flow-induced voltage. It is worth mentioning that the transformer noise exists even when the flow is stopped because it is generated due to the interaction of the applied magnetic field and the measuring closed loop. Hemp and Youngs [21] have reported an approximate calculation of transformer signal for fully filled pipes:

$$
E s=-i \omega B \pi b^{2} F
$$

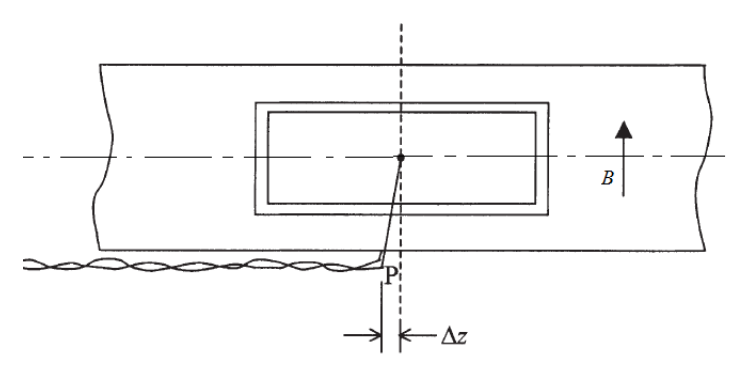

(a)

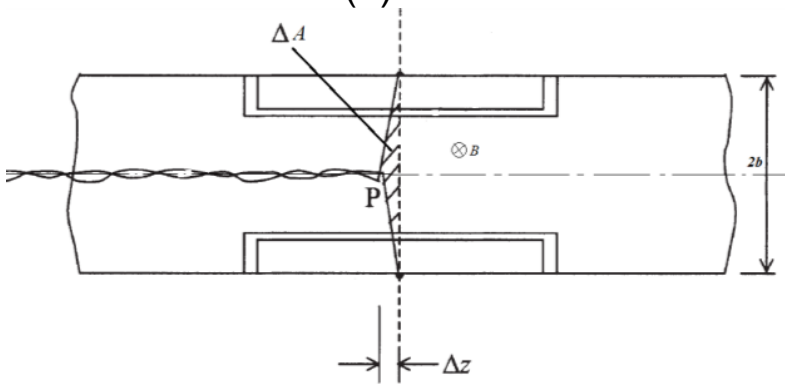

(b)

Figure 2: Origin of transformer noise in fully filled pipes for two views (a) and (b). 


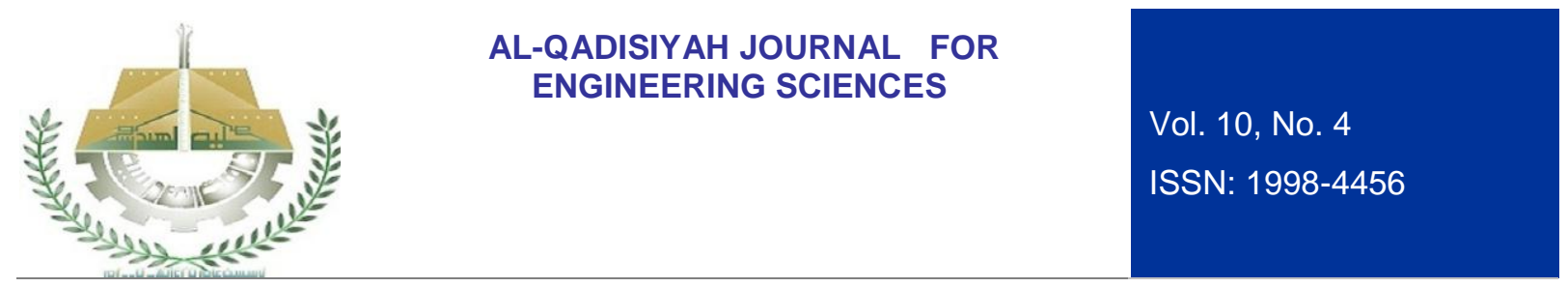

Where $\omega$ is the angular frequency, $B$ is the magnetic flux, $b$ is the radius of pipe shown in Figure 2 , and $F$ is a dimensionless number calculated as follows [21] (Figure 2):

$$
F=\frac{1}{\pi} \frac{\Delta z}{b}
$$

\section{EXPERIMENTAL SET UP}

Generally, in conventional electromagnetic flowmeters, a great attention is done to obviate the unwanted noise signal and especially the transformer signal. The general procedure followed for this task is a common electronic circuit known as a phase sensitive detector (P.S.D.). The attention of the present study is focused on the experimental analysis of such transformer signal. To achieve the related experiments, it is required to build a real rig consists of a real laboratory electromagnetic flowmeter provided with many supplementary measurement instruments to assist in collecting a huge experimental data. As mentioned previously, the transformer noise is generated due to the interaction between the applied magnetic field and the loop composed of electrodes leads, liquid path, and the instrument that reads the output signal. In other words, the transformer noise exists even when the flow is stopped. This feature serves in reducing the efforts of the experimental work, i.e. the experiments are conducted with no flow provided that the liquid and the magnetic field exist in the flowmeter tube. The main two elements in the present study are as follows:

\subsection{PRIMARY ELEMENT}

The material of the metering tube must be electrically insulated to prevent the shorting of the level induced signal and non-magnetic in order to avoid its effect on the magnetic field across the fluid. For this purpose, a PVC pipe with an inner diameter of $107.2 \mathrm{~mm}$ and outer diameter of $110.6 \mathrm{~mm}$ was elected. A $500 \mathrm{~mm}$ length of this pipe was cut to achieve a flowmeter length of about $5 \mathrm{D}$. This length is sufficient to ascertain the end boundary conditions of electromagnetic flowmeter. The level signal is decided to be picked up by point electrode type because this type is easiest to implement, most reliable and it is more convenient for the purpose of the present aim. The optimum position of these electrodes is about $53^{\circ}-160^{\circ}$ (six pairs of electrodes) below, upper and in the center of the level meter pipe horizontal axis [14], so the experiments are enabled to be conducted even when the liquid level drops to $0.03 \mathrm{D}$ (Figure 3). For comparison enhancement purpose and to expand the experiments to cover fully filled experiments it was decided to distribute these electrodes on the specified distance from each other, of course each opposite pair works individually, were arranged on the level meter liner. These electrodes were manufactured from a $4 \mathrm{~mm}$ diameter, $316 \mathrm{~L}$ stainless steel rod. This (non-magnetic) material has a very good resistance to wear and corrosion also; it has high electrical conductivity property. The best electrode to pipe diameter ratio is 1/20 [22] hence, $4 \mathrm{~mm}$ electrode diameter is the commercially available that is closest to this ratio. Each electrode has a length of $7 \mathrm{~mm}$ and fixed in a drilled hole through the liner in such a way to be flushed with the inner surface of the liner.

\subsection{SECONDARY ELEMENTS}

In conventional electromagnetic flowmeter, the task of the electronic circuit is to amplify and demodulate the voltage picked up by the electrodes. The demodulation refers to the phase shift between the flow signal and the transformer signal, which is equal to $90^{\circ}$. The famous relatively simple technique used for this purpose known as the phase-sensitive detection (P.S.D.). The phase-sensitive detector is an appliance, which multiplies the buffered electrode signal by +1 and -1 at a rate determined by a control signal. The control signal (usually square wave) must be in phase with the flow signal and hence with the magnetic field excitation, it may be driven from the excitation source. A schematic diagram of the phase-sensitive detector is illustrated in Figure 4 The details of the real electronic components of this circuit are illustrated in [14]. Keeping in mind that our experiments are to be conducted with no flow, a slight modification was made on the 
circuit that is canceling the averaging stage, i.e. the electrode (transformer) signal is permitted to pass as AC rather than DC signal (Figure 5). In general, the idea of the present technique is to operate the EMF with allowing the transformer signal for a while to measure the liquid level and then attenuating this signal to measure the flow signal. This process can be achieved by providing the EMF by a simple selector switch. Figure 6 shows the real experimental set up.

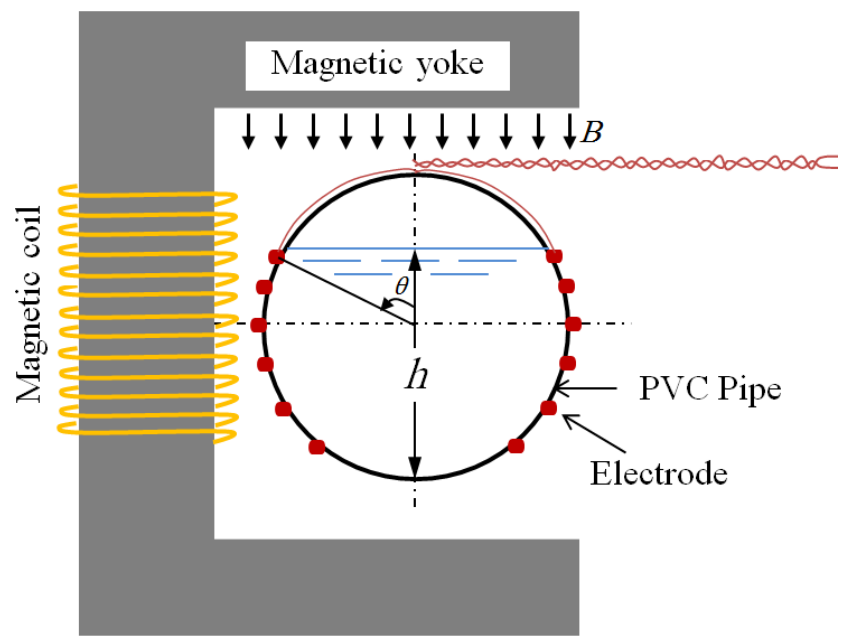

Figure 3: The liner and the electrode system assembly.

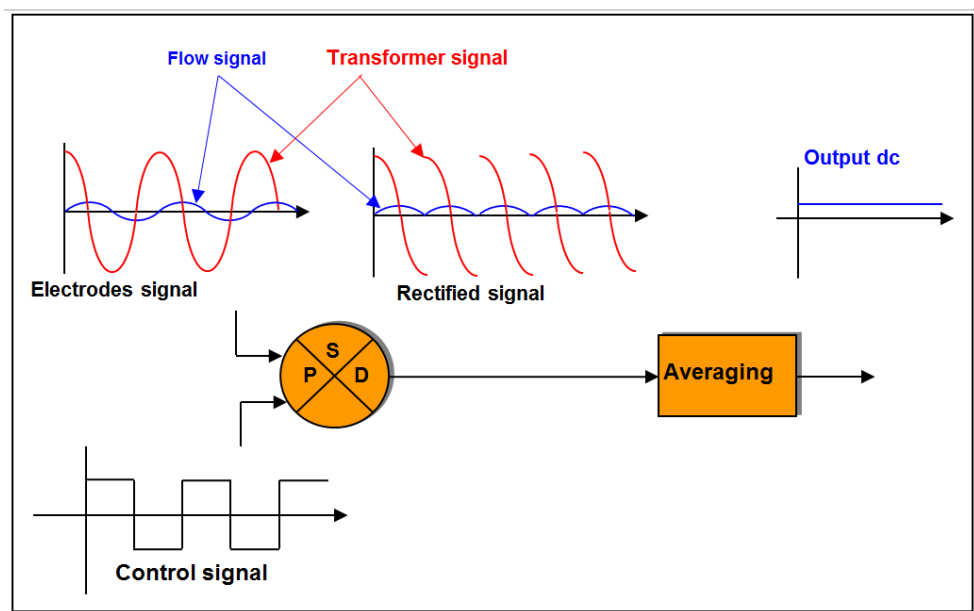

Figure 4: Conventional Phase sensitive detector with liquid flow [14]. 

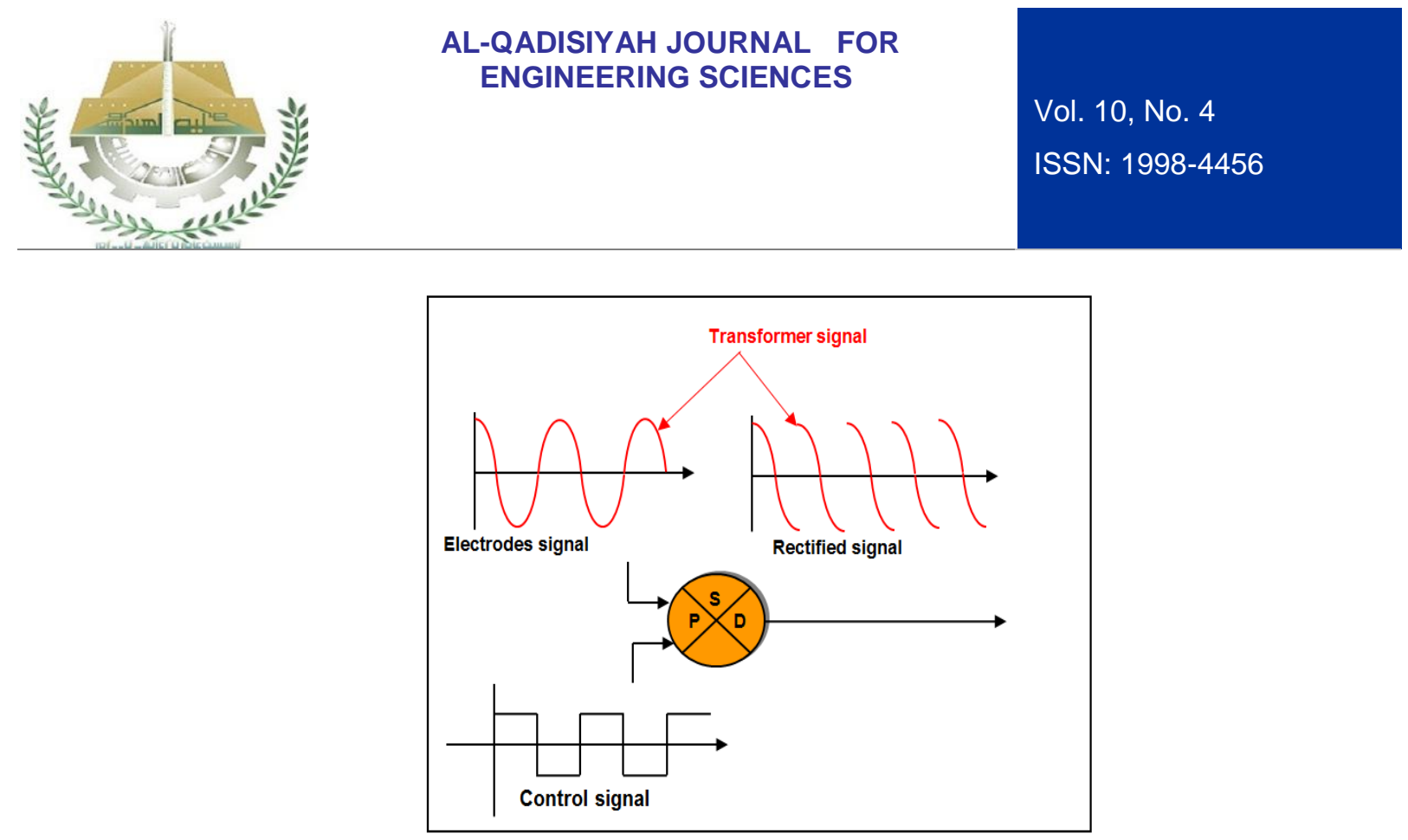

Figure 5: Present using of the phase sensitive detector with no flow [14].

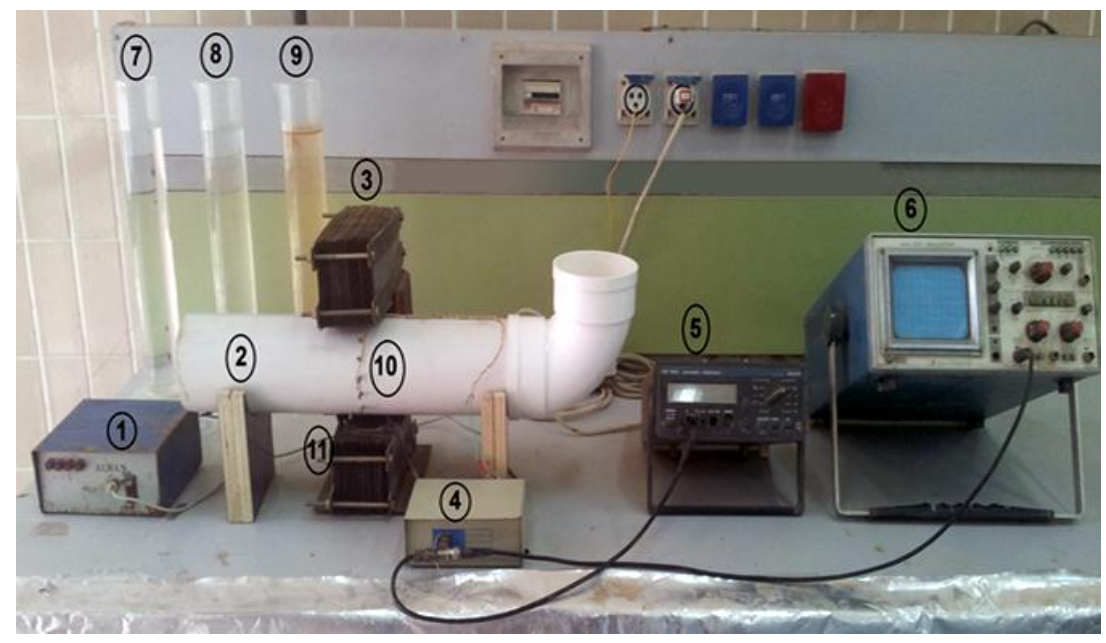

Figure 6: The testing rig and instrumentations (1)- D.C. power supply (2)- Testing Tube (3)- The magnet (4)-Signal processor (5)- multi-meter (6)- Oscilloscope (7)-Mineral Water tube (8)- Tap Water tube (9)Salt Water (10)- The electrodes (11)- Reference signal.

\section{RESULTS AND PROCESSING}

\subsection{RAW RESULTS}

The main laboratory experimental measurements were represented by varying the liquid level, and measuring the generated transformer signal from each pair of electrodes. This procedure has been repeated for three types of liquid these; mineral water, tap water and well salt water with electrical conductivity $\sigma$ of $0.11225,3.08$ and $210 \mathrm{mS} / \mathrm{cm}$, respectively. The applied magnetic field was varied as, $B=0.0809,0.03308$ and 0.05301 Tesla. The experimental measurements have been carried out at different temperatures, $T=11$ $-21.5^{\circ} \mathrm{C}$. In all measurements, the transformer signal was recorded as D.C. signal. However, in the following displayed experimental results we have chosen $B=0.03308$ Tesla and $T=11^{\circ} \mathrm{C}$. 


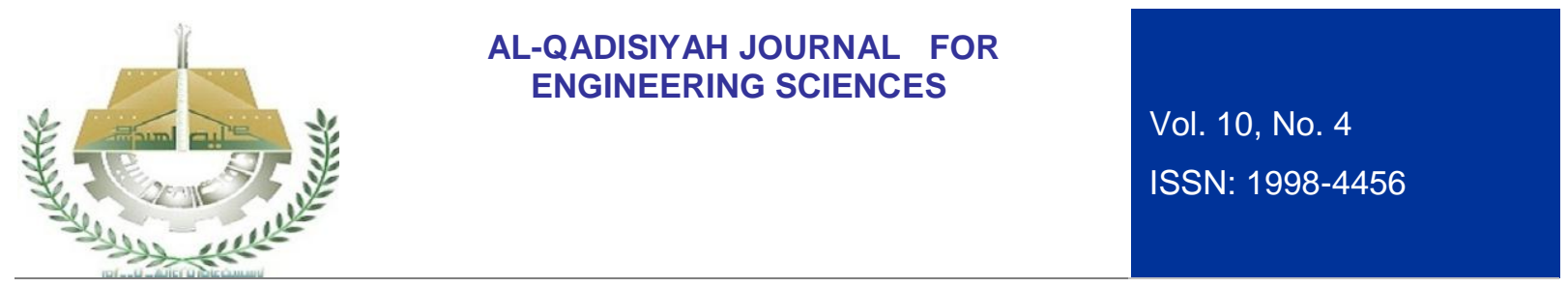

Figure 7 depicts the data of upper electrode position $\left(\theta=53^{\circ}\right)$, it is clear from this figure that the sensed liquid level is limited to be $8.295 \mathrm{~cm}$ only. The magnitude of the transformer noise is greater according to the following sequence: mineral water, tap water, salt water. This is because of the wide range shift in the electrical conductivity. The values of salt water are about 15 times less than the other two water types, this due to the great shift of the electrical conductivity of salt water, which is about 70 times larger than that of tap water. Figure 8 shows the results of electrode position, $\theta=90^{\circ}$, at the mid-level meter plane. In this position, the sensed liquid level is lowered to $5.53 \mathrm{~cm}$. It can be seen from this figure that in the case of salt water, the transformer noise signal is slightly changed with the liquid level. The reason of such behavior was unclear at the early stages of data recording, but with many repeated data, the explanation of such behavior was attributed to the contamination process of deposits on the electrodes inner surface, where the salt water contains many sediments and composition.

Figure 9 shows the lower electrode position measurements $\left(\theta=160^{\circ}\right)$. The sensed liquid level is further lowered to $0.6 \mathrm{~cm}$. It is worth mentioning here that an electrode position lower than the conventional position $\left(\theta=90^{\circ}\right)$ is highly recommended for partially filled electromagnetic flowmeter [14]. However, the present results appear to be more stable and smooth with fewer problems. By referring to Figures 7 and $\mathbf{8}$, it can be seen that when the liquid level falls to be close to the electrode surface, the transformer signal increases sharply. This abrupt change in the transformer signal is not seen at the lower electrode position $(\theta$ $=160^{\circ}$ ). The reason of this phenomenon may refer to the asymmetry of liquid quantities over and under the electrodes connecting line. The liquid quantity governs the number of paths of transformer current. However, when the electrode positioned under the conventional position $\left(\theta=90^{\circ}\right)$, the effect of liquid symmetry is reduced as the liquid quantity below the electrode plan is already small.

In general, it is noticed (in all electrode positions) that when the liquid level increases, the magnitude of the transformer noise signals is decreased. This behavior is observed in all recorded data which are reached to (690) readings (these data are not displayed for brevity). This behavior can be attributed to the following: increasing the liquid level leads to the increase of the equivalent resistance (Figure 1), hence the generated current will be reduced meanwhile the decrease of the liquid level leads to lowering the number of equivalent resistors which in term results in an increasing the transformer current.

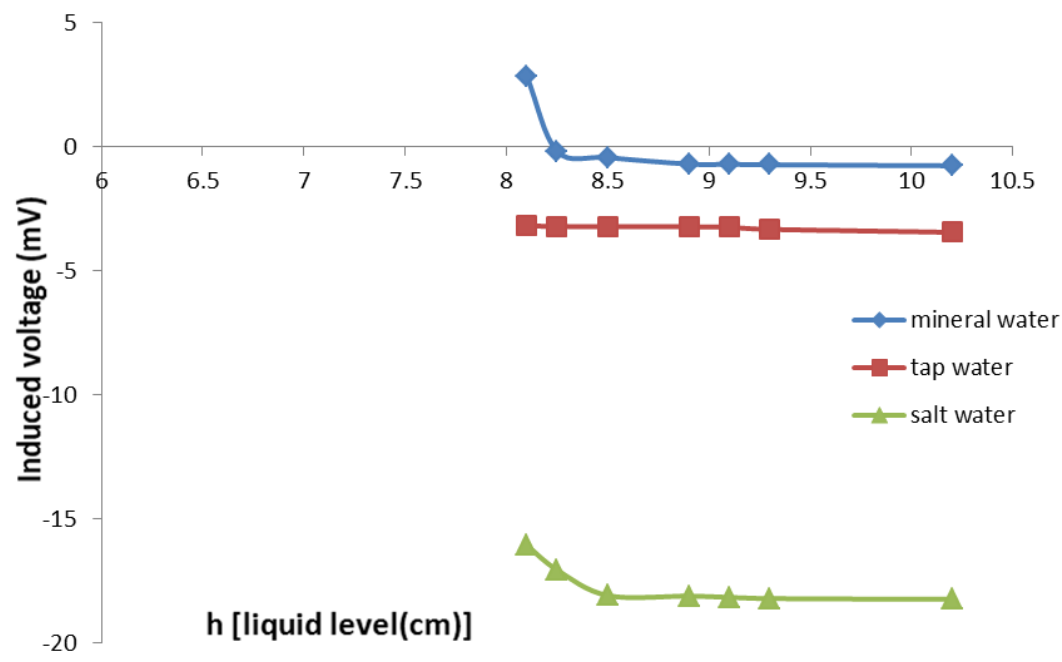

Figure 7: Variations of the induced signal with changing liquid level at $53^{\circ}$ electrode position and 0.03308 Tesla of magnetic field and $T=11^{\circ} \mathrm{C}$. 


\section{AL-QADISIYAH JOURNAL FOR ENGINEERING SCIENCES}

Vol. 10 , No. 4

ISSN: $1998-4456$

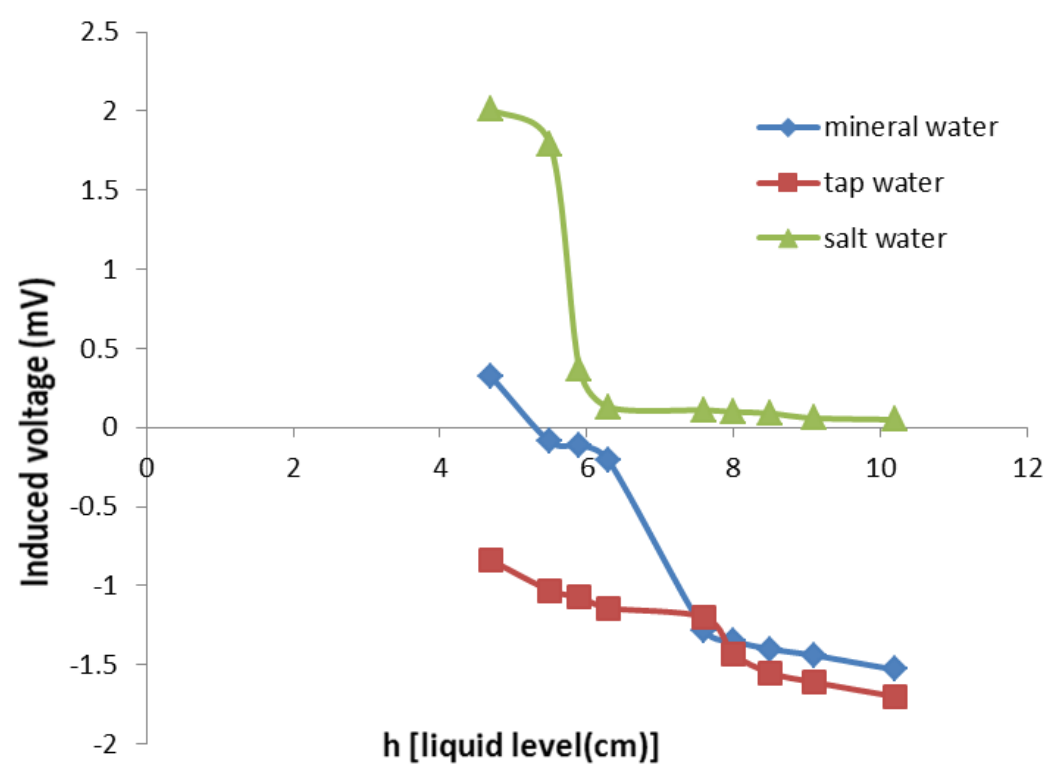

Figure 8: The variation of the induced signal with changing liquid level at $90^{\circ}$ electrode position and 0.03308 Tesla of magnetic field and $T=11^{\circ} \mathrm{C}$.

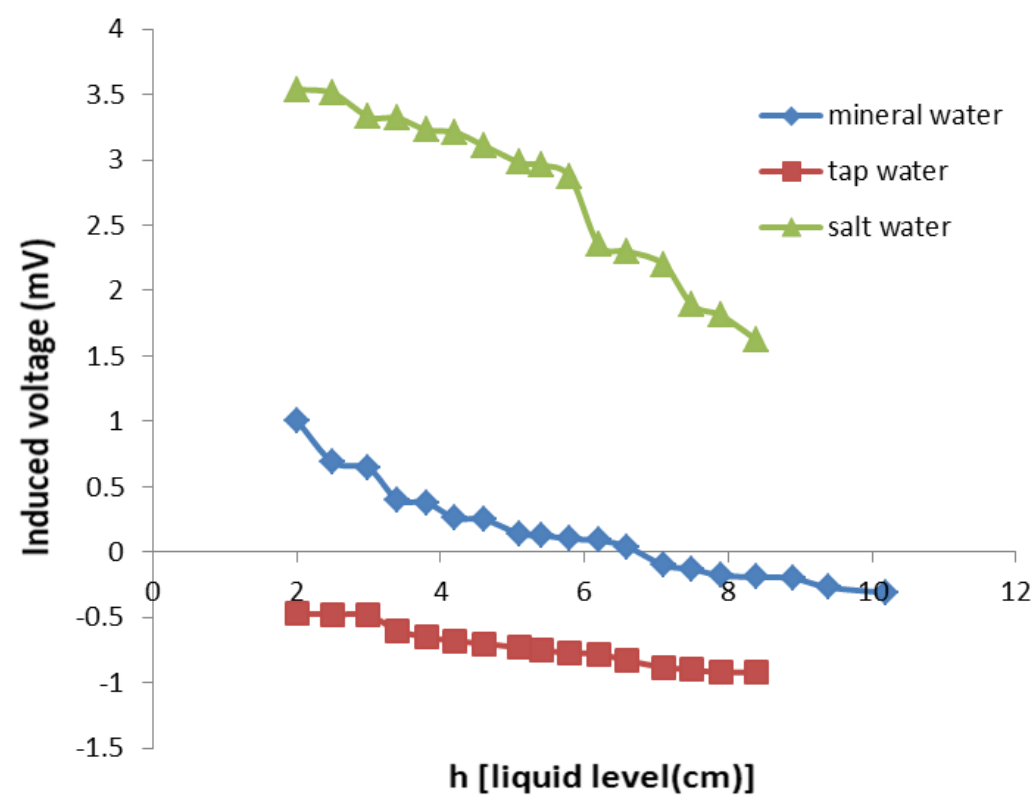

Figure 9: The variation of induced signal with changing liquid level at $160^{\circ}$ electrode position and 0.03308 Tesla of magnetic field and $T=11^{\circ} \mathrm{C}$. 


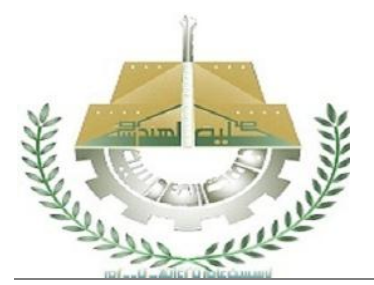

\section{AL-QADISIYAH JOURNAL FOR ENGINEERING SCIENCES}

\section{Vol. 10 , No. 4}

ISSN: $1998-4456$

However, it is found that analyzing these huge data directly does not give comprehensive information about the real relation between the liquid level and the recorded signal. Therefore, the study is turned to use another technique, namely the Artificial Neural network ANN.

\subsection{ANN MODEL}

Artificial neural networks are non-linear mapping structures based on the function of the human brain. They are powerful tools for modeling, especially when the underlying data relationship is unknown. ANNs can identify and learn correlated patterns between input data sets and corresponding target values [23]. Neural networks are composed of simple elements operating in parallel. Commonly neural networks are adjusted, or trained, so that a particular input leads to a specific target output. Such a situation is shown in Figure 10.

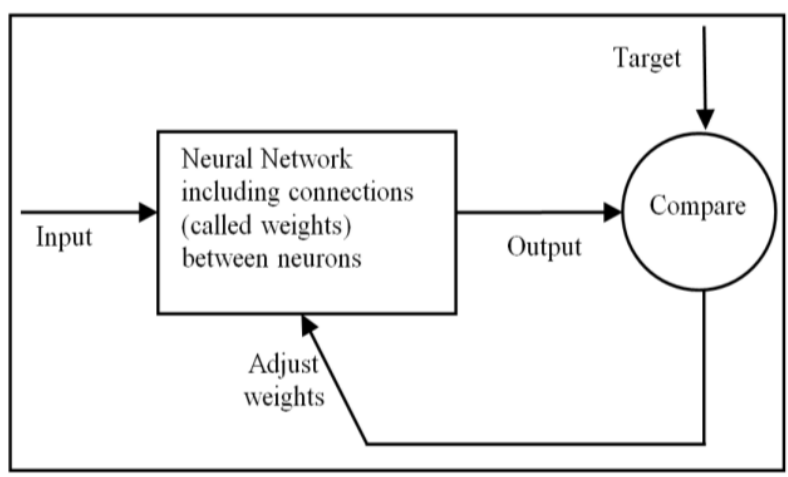

Figure 10: Basic operation of ANN.

The neural network model is developed to predict the liquid level which depends on the results of the experimental work as training and testing data. The total experimental data are divided into two sets: a training set and a testing set. The training set is used for computing the gradient and updating the network weights and biases to diminish the training error, and find the relationship between the input and output parameters. The test set is used to evaluate the generalization ability of the learning process. In this study, the testing set contains approximately $20 \%$ of total the database. The total number of (690) test cases were utilized. The training set contains (552) cases and the testing set comprises of (138) cases. The parameters used in this study are shown in Table 1.

Table 1: Input and Output Parameters.

\begin{tabular}{|c|c|c|c|c|}
\hline \multirow{2}{*}{ Item } & \multirow{2}{*}{ Parameters } & \multicolumn{2}{|c|}{ Range of Parameters } & \multirow{2}{*}{ Units } \\
\hline & & From & To & \\
\hline \multirow{5}{*}{$\begin{array}{l}\text { Input } \\
\text { Parameters }\end{array}$} & Transformer Noise in Voltage (V) & -18.23 & 4.95 & $\mathrm{mV}$ \\
\hline & Electrode Position $(\theta)$ & 53 & 160 & degree \\
\hline & Strength of Magnetic field $(B)$ & 0.00809 & 0.05301 & Tesla \\
\hline & Electrical Conductivity $(\sigma)$ & 0.1225 & 210 & $\mathrm{mS} / \mathrm{cm}$ \\
\hline & Water Temperature $(T)$ & 11 & 21.5 & ${ }^{\circ} \mathrm{C}$ \\
\hline $\begin{array}{l}\text { Output } \\
\text { Parameter }\end{array}$ & Liquid Level (h) & 0.8 & 10.2 & $\mathrm{~cm}$ \\
\hline
\end{tabular}




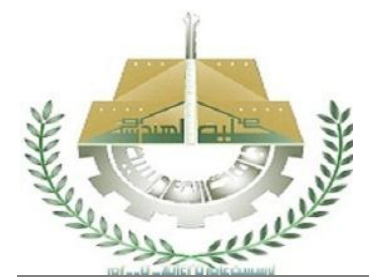

\section{AL-QADISIYAH JOURNAL FOR ENGINEERING SCIENCES}

\section{Vol. 10 , No. 4}

ISSN: $1998-4456$

\subsection{THE PROPOSED NETWORK}

In this study, the network is tested with different number of hidden layer configurations with an increasing number of nodes in each hidden layer(s). Different activation function arrangements are investigated. The optimal topology is determined using the conjugate gradient back-propagation with PolakRibiere update (TRAINCGP) as a training function with activation function as hyperbolic tangent (tansig) function for two hidden layers and output layer. The used ANN was implemented in MATLAB 2009. The proposed network gives the best mean square error (MSE) and correlation factor ( $r$ ) for both training and testing data as shown in Figure 11. The optimal structure of the proposed network is 5:16:19:1 topology (5 neurons in input layer, 16 neurons in the first hidden layer, 19 neurons in the second hidden layer and a single neuron in the output layer) as shown in Figure 12.

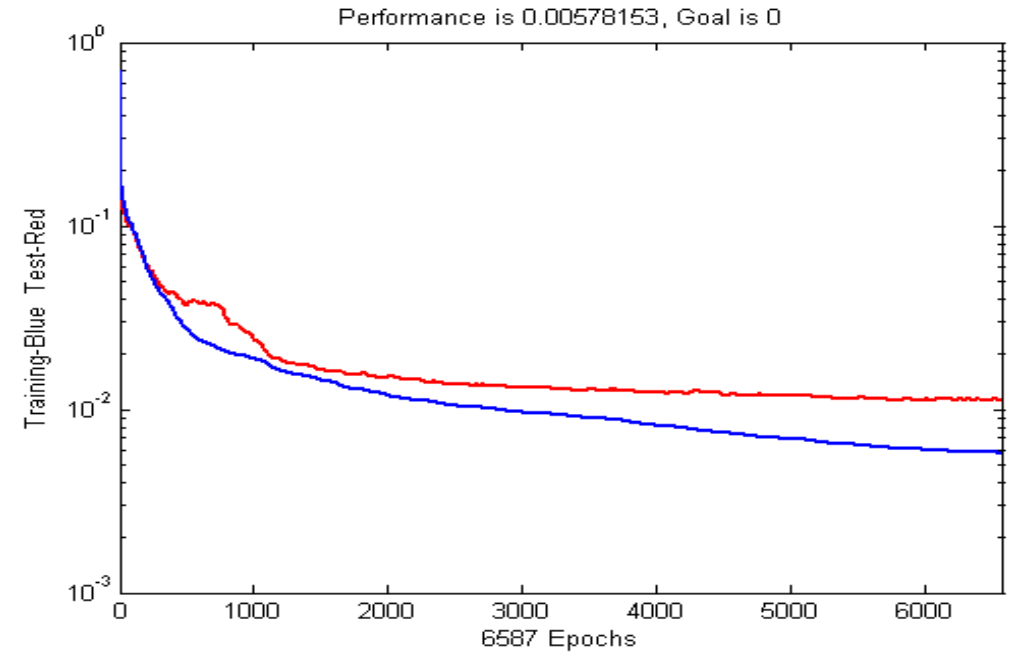

Figure 11: Train and test MSE vs. epochs of the best two hidden layer network.

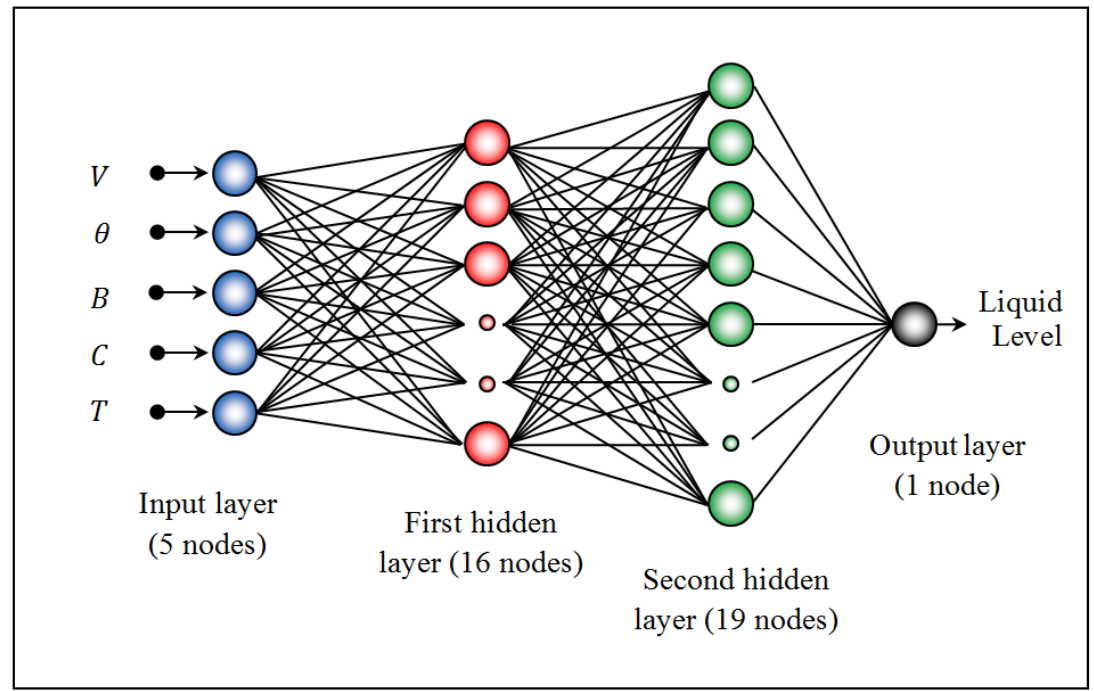

Figure 12: Configuration of neural network structure (5-16-19-1). 


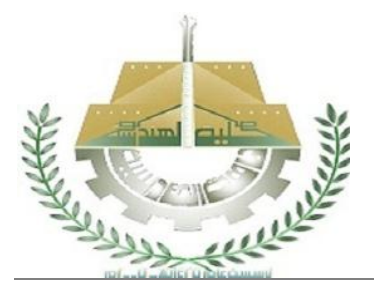

\section{AL-QADISIYAH JOURNAL FOR ENGINEERING SCIENCES}

Figures 13 and 14 present the outputs versus the targets as open circles. The solid line indicates the best linear fit and the dashed line indicates the perfect fit (output equals target). The values of the slope are $(0.963)$ and $(0.952)$ respectively, interceptions with y-axis are $(0.226)$ and $(0.349)$ respectively, and correlation coefficients are (0.988) and (0.975) respectively. These values indicate that the mapping of neural network for the training and testing data is very good.

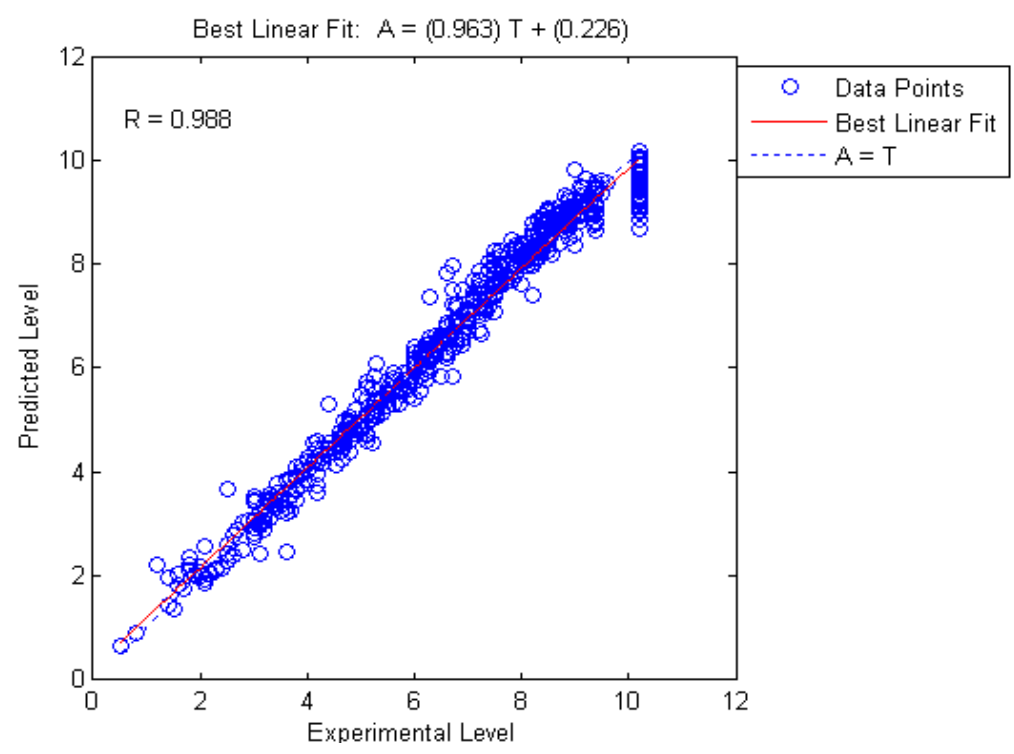

Figure 13: Training regression of the proposed two hidden layer network.

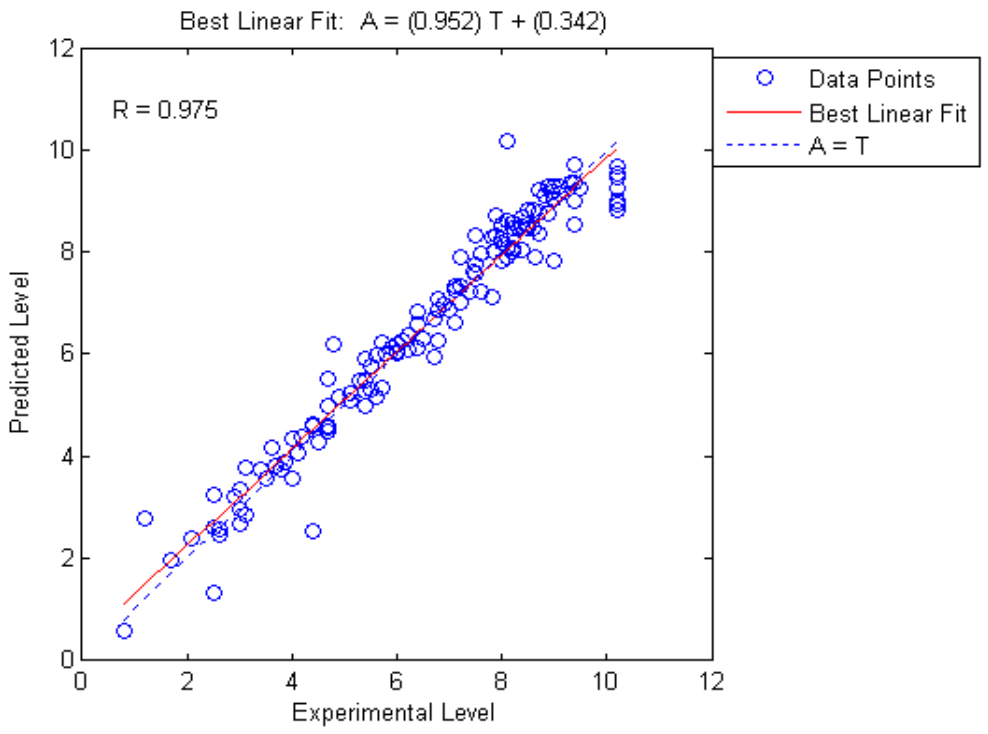

Figure 14: Testing regression of the proposed two hidden layer network. 
Figures 15 to 17 show a comparison between the experimental results and ANN model against the effect of changing in the induced voltage to the liquid level for three types of water (mineral, tap, salt) at constant magnetic field $\left(0.03308\right.$ Tesla), constant temperature $\left(T=11^{\circ} \mathrm{C}\right)$ and at electrode position $\theta=53^{\circ}$ (The other positions are not shown for brevity). These comparisons confirm the obtained results from the ANN model represent good result.

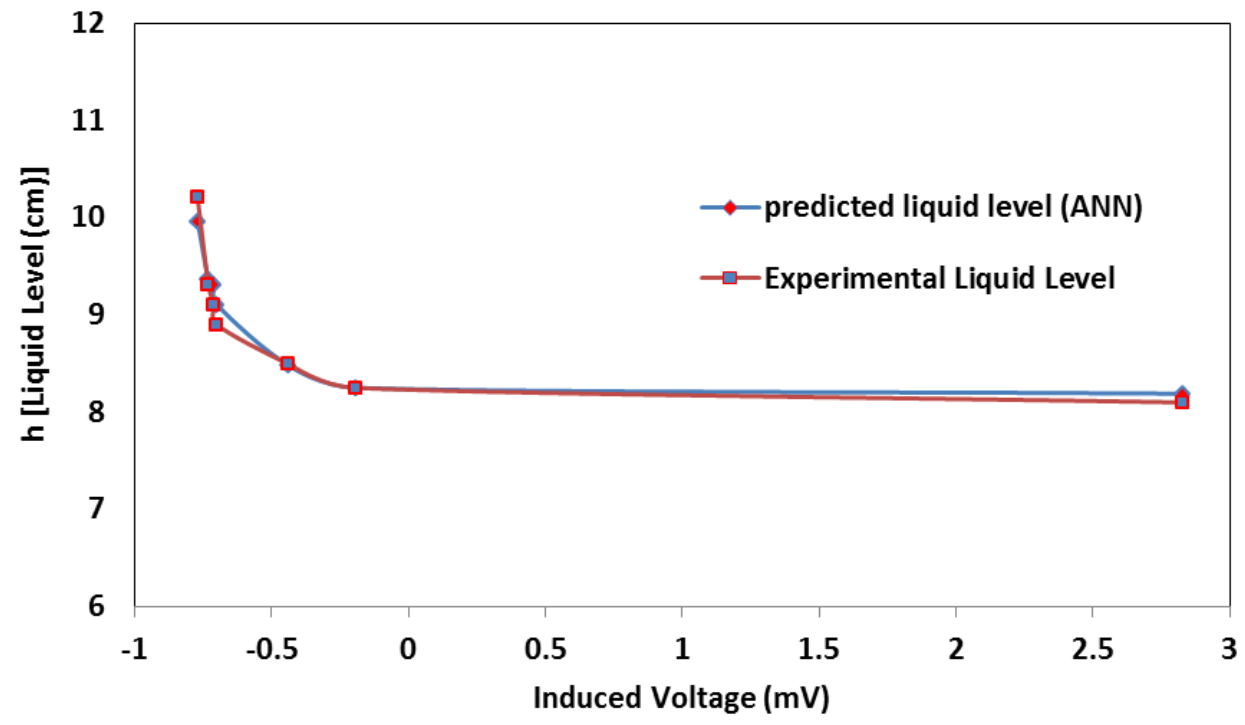

Figure 15: Comparison between the experimental result and neural network result of mineral water liquid type at electrode position $53^{\circ}$ and magnetic field 0.03308 Tesla and $T=11^{\circ} \mathrm{C}$.

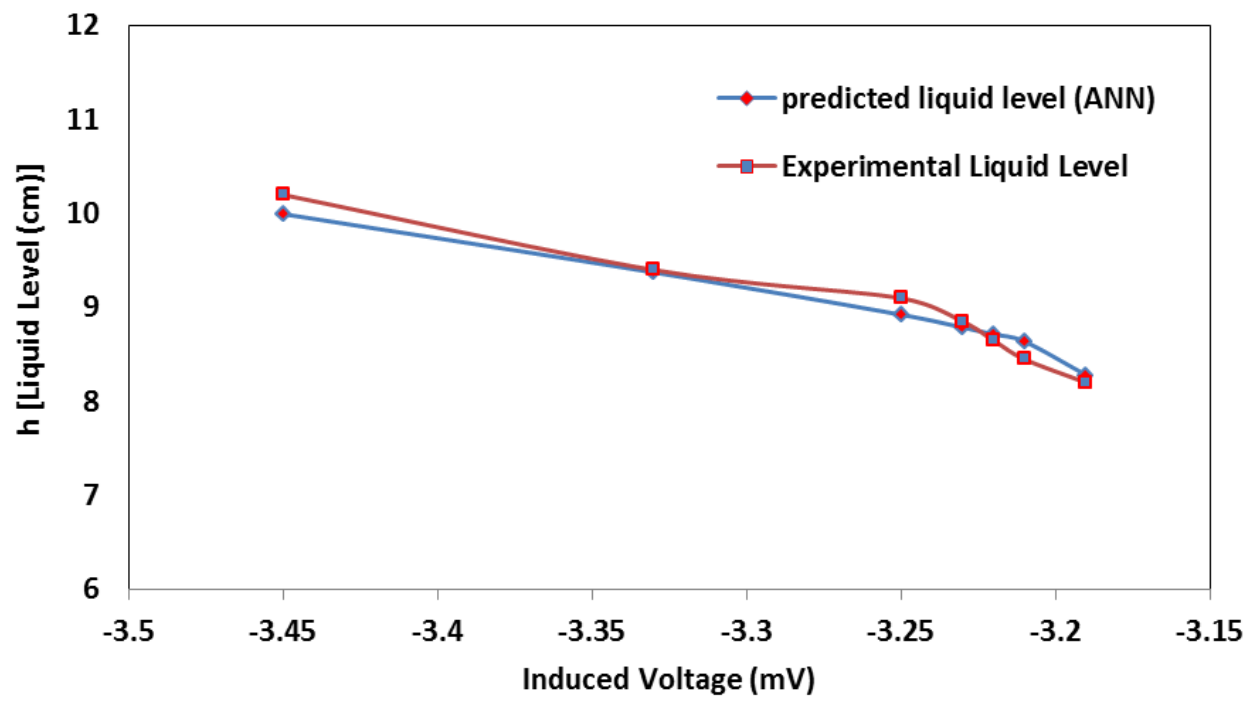

Figure 16: Comparison between the experimental result and neural network result of tap water liquid type at electrode position $53^{\circ}$ and magnetic field 0.03308 Tesla and $T=11^{\circ} \mathrm{C}$. 

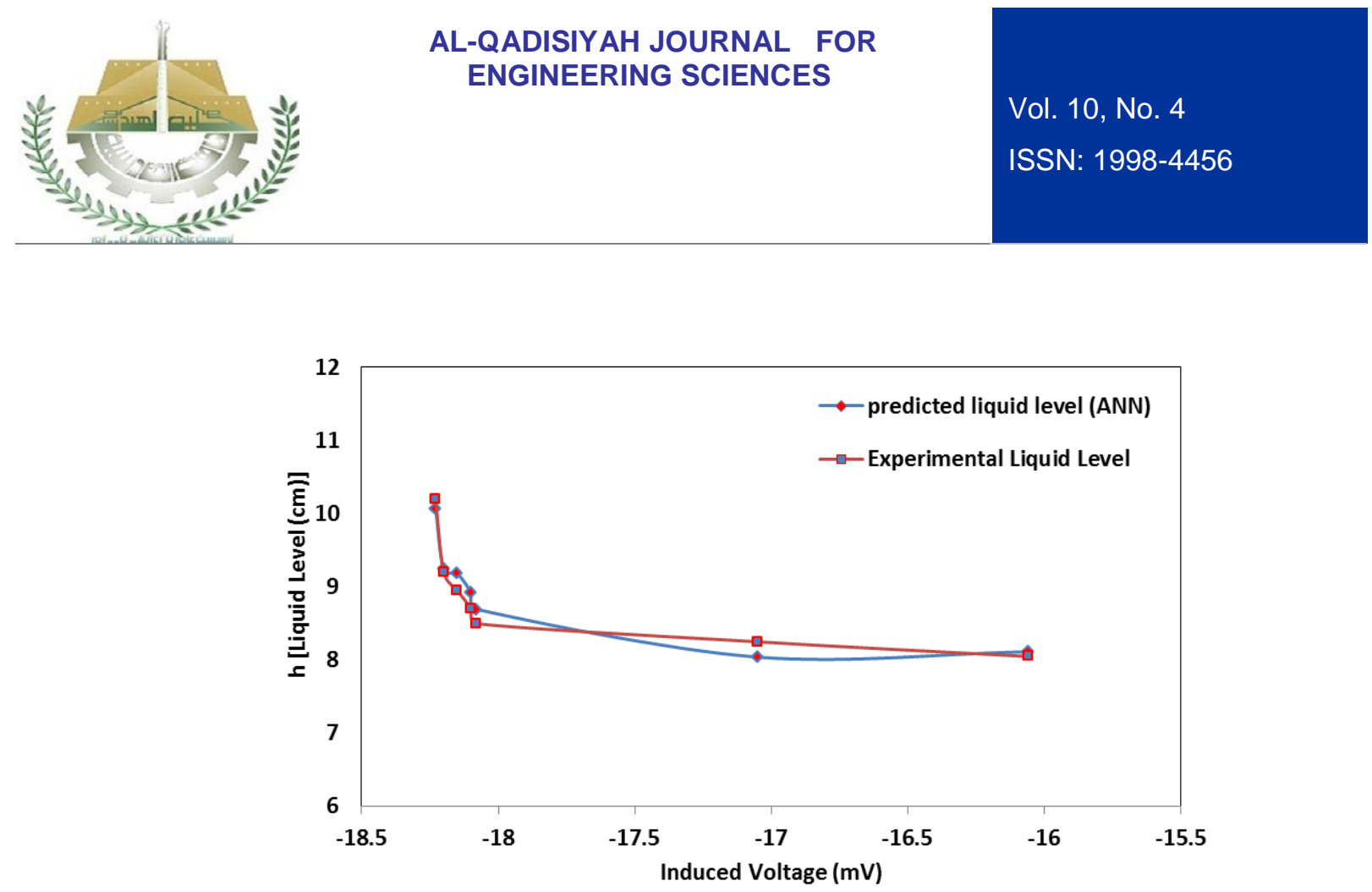

Figure 17: Comparison between the experimental result and neural network result of salt water liquid type at electrode position $53^{\circ}$ and magnetic field 0.03308 Tesla and $T=11^{\circ} \mathrm{C}$.

\section{CONCLUSIONS}

The present paper investigates, experimentally and statistically, the possibility of utilizing the inherent transformer noise signal in electromagnetic flowmeter to measure the liquid level of partially filled pipes. The nonlinearity and complexity of the relation govern the transformer signal motivate the use of the artificial neural networks to deal with the extracted huge experimental data. The back propagation neural network, which is a multi-layered feed forward neural network, has been proven to accurately predict the liquid level that increases the accuracy and reduces the cost of electromagnetic flowmeter when it designed for the partially filled pipes. The most important conclusions that can be drawn from the present study are the followings:

- The liquid level is the stronger parameter that affects the transformer noise signal than other parameters.

- The transformer signal increases with the decrease of the liquid level and vice versa.

- The transformer signal generated with salt water is prominent with respect to those generated with mineral and tap water. For example, when $\theta=160^{\circ}, B=0.03303$ Tesla, $T=11^{\circ} \mathrm{C}$ and $h=2 \mathrm{~cm}$, the salt water signals are 2.5 times and 7 times greater than mineral and tap water, respectively.

- Two hidden layers neural network model significantly improves the performance of the network. The configuration (16-19) (16 nodes in the first hidden layer, and 19 nodes in the second hidden layer) is proved to be very efficient for predicting the liquid level.

- The conjugate gradient backpropagation with Polak-Ribiere updates (TRAINCGP) algorithm gives better performance and regression for both training and testing phases.

\section{BIODATA}

-Muneer A. Ismael is assistance professor (PhD) at University of Basrah, Engineering College, Department of Mechanical Engineering. His interested researches are electromagnetic flowmeters, nanofluid, and mixed convection.

-Rafil M. Laftah is a lecturer (PhD) at University of Basrah, Engineering College, Department of Mechanical Engineering. His interested researches are fracture mechanics, artificial neural network, and finite element.

-Mustafa N. Falih is MSc. student in University of Basrah, Engineering College, Department of Mechanical Engineering. He is an engineer in South Oil Company, Basrah, Iraq. 


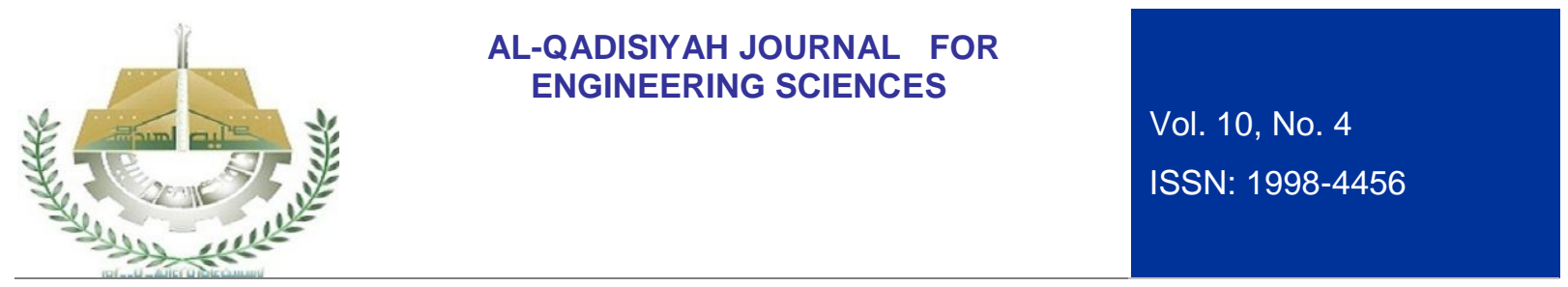

\section{REFERENCES}

1. Baker, R.C., Flow measurement handbook, industrial design, operating principals, performance and applications. Cambridge University press, $1^{\text {st }}$ ed., UK, 2000.

2. Hemp, J., Theory of eddy currents in electromagnetic flowmeter, in "Journal of Physics D" 24, 1990, pg. 244-251.

3. Al-Rabeh, R.H.; Baker, R.C., On the ability to dry calibrate an electromagnetic flowmeter, in „Journal of Physics E" 19, 1986, pg. 203-206.

4. Hemp, J., A technique for low cost calibration of large electromagnetic flowmeters, in „Flow Measurement and Instrumentation" 12, 2001, pg. 123-134.

5. Bates, J.C.; Franklin, B., The performance characteristics of a novel multi-electrode electromagnetic flowmeter, in „Measurement” 35, 2004, pg. 399-408.

6. Rosales, C.; Sanderson, M.L., Streaming current noise generation in electromagnetic flowmeters measuring conducting fluids, in „Flow measurement and Instrumentation” 14, 2003, pg. 97-108.

7. Mannherz, D.E.; Yard, J.S., Electromagnetic flowmeter usable in less than full fluid lines, in „US Patent” 3,991,612, 1976.

8. Searle J.L., Electromagnetic flowmeter usable in less-than full fluid lines, in „U.S. patent” 4,036,052, 1977. 9. Marsh, L.B., Fluid Flow Meter, in „U.S. patent” 4,083,246, 1978.

10. Bonfig, K.W., New developments in magnetic flow measurement in partly filled open channels, Technical and mythological in measurement, in „9th IMEKO water conference” 1982, pg. 131-140.

11. Barker, L.W., Method and apparatus for measuring total liquid volume flow, in „U.S. patent” 4,393,451, 1983.

12. Doney, B., Electromagnetic flow measurement in partially filled pipes, in „Journal of Fluid piping Systems", magnetic flow products for ABB instrumentation, 1999.

13. Godley, A., Flow measurement in partially filled closed conduits, in „Flow measurement and Instrumentation", 13, 2002, pg. 197-201.

14. Ismael, M.A., Adaptive numerical solution and experimental study into the design of the electromagnetic flowmeter for partially-filled pipes, Ph.D. Thesis, University of Basrah, 2007.

15. Lucas, G.P.; and Leeungculsatien, T., A new method of measuring velocity profiles using a multielectrode electromagnetic flow meter, in "6th World Congress on Industrial Process Tomography, 69 September 2010, Beihang Conference Center, Beihang University, China.

16. Jia, S.; Chunqing, Q.; Hongbin, Z., Multi-parameters measurement based on STM32 ARM of dualexcited electromagnetic flow meter in partially filled pipes, in „Applied Mechanics and Materials' vol. 347-350, 2013, pg. 682-685.

17. Watral, Z.; Jakubowski, J.; Michalski, A., Electromagnetic flowmeters for open channels: Current state and development prospects, in „Flow Measurement and Instrumentation” 42, 2015, pg. 16-25.

18. Justensen, J.C., The effects of meter orientation downstream of a short radius elbow on electromagnetic flow meters, MSc. Thesis, Utah State University, 2016.

19. Shercliff, J.A., The theory of electromagnetic flow-measurement, Cambridge University press, UK, 1962. 20. Mannherz, D.E.; Yard J.S., Electromagnetic flowmeter usable in less-than full fluid lines, in "US patent” 3,991,612, 1976.

21. Hemp, J.; Youngs, I., Problems in the theory and design of electromagnetic flowmeters for dielectric liquids. Part 3a. Modelling of zero drift due to flux linkage between coil and electrode cables, in „Flow Measurement and Instrumentation" 14, 2003, pg. 65-78.

22. Hemp, J.; Wyatt, D.G., A basis for comparing the sensitivities of different electromagnetic flowmeters to velocity distribution, in „Journal of fluid Mechanics” 112, 1981, pg. 189-201.

23. Engelbrecht, A.P. Computational Intelligence, 2nd ed. John Wiley \& Sons Ltd, England, 2007. 